\title{
Transport system as a factor of the urban development in the XXI century: the Russian capital example
}

\author{
Igor Pryadko ${ }^{1}$ and Elena Vasilyeva ${ }^{1, *}$ \\ ${ }^{1}$ Moscow State University of Civil Engineering, Yaroslavskoye sh., 26, Moscow, 129337, Russia,
}

\begin{abstract}
In this research project the co-authors bring up a most serious problem, that is, biosphere compatibility of urban space planning; this problem is to be solved though development of an urban environment which is barrier free for any urban transport; the solution also contemplates the availability of urban transport routes free from any traffic jams. The coauthors consider different techniques that serve to develop comfortable transport links. A comfortable transportation network boosts the sustainability of any urban economy. The co-authors analyze the following trends in sustainable road building: top priority development of public transport networks, construction of public transport hubs, broadened road paving and bus lanes, and replacement of diesel-fuelled vehicles by electric buses. In this work, the co-authors analyze the findings of an opinion poll on transportation priorities expressed by Moscow residents. Different means of public transport are analyzed in the work, namely, electric buses are compared to trolley-buses and diesel-fuelled vehicles.
\end{abstract}

\section{Introduction}

One of the main tasks of modern urbanistics is the development of models of such a transport system which would satisfy the needs of a modern megalopolis which extended its infrastructure to huge territories. The synthesis of the experience, accumulated by municipal authorities in the sphere of road construction as well as the creation of favorable and convenient network of transport connection is of great importance.

Biosphere compatibility comprises a rational public transport network. Therefore, models of future smart cities have their built environments stretched along major transportation routes. On the one hand, a rational transport network, developed in compliance with the principles of green urban design, ensures quick access to various urban districts, and, on the other hand, this network is designated to reduce pressure exerted on the Earth's shells within city limits, and this is a challenging task.

In the early 20ieth century European and North American cities smothered with exhausts, while multiplication of the urban car fleet caused traffic delays in urban streets and artery roads, and, ultimately, put urban traffic to a halt. Biosphere compatible road

\footnotetext{
*Corresponding author: elena.chibisova_metr@mail.ru
} 
building, launched in the countries having the most advanced technologies at their disposal, is designated to overcome these difficulties.

In this article, the co-authors will discuss the following four constituents of the transport problem: connection hubs in the Russian capital; prospects for development of subterranean vehicles and electric power driven transport; preferable means of transport.

\section{Materials and Methods}

The statements made in the preceding paragraph enable us to determine the object and the subject of this research, as well as its methods and objectives. In this paper, the co-authors are going to describe the changes that are underway and to shed light on the reasons behind them. Therefore, the objective of this work is not only to describe the problem, but also to analyze it. The co-authors will use Moscow transportation arrangement patterns as a model. The co-authors will analyze particular constituents of the transportation development pattern both in the old districts of Moscow and its newly annexed areas. The challenge is to employ particular cases to demonstrate the most important milestones in development of transportation networks in megalopolises and to find out what means of transport Muscovites prefer. The objectives set in the article have pre-determined the optimal methods for their attainment.

Let's identify the list of methods and theoretical approaches applied in this work. First of all, the co-authors apply sociological and general scientific methods of data analysis. The sociological methods, applied in this research, include the retrospective analysis of the data published by media agencies, findings of the opinion polls launched to learn the opinions of Moscow residents, and urban planning concepts. On top of specialized methods of research, the co-authors also employ methods of deduction, induction, inference by analogy, and modelling. The poll was conducted in the form of printed questionnaires; hence, interaction between the interviewer and the respondent was mediated by the questionnaire. 125 residents of Moscow and Moscow Metropolitan area participated in the poll. The poll was launched in October 2018 as part of a sociological survey conducted by the employees and senior students of NRU MGSU.

The data of the Internet poll held by My Region Newspaper (special issue of Evening Moscow ) among the inhabitants of new territories of the city are also considered within the research. The poll took place in June, 2019 in the community of the settlements residents vk.com/numsk. The residents of the Novomoskovsk and Troitsk administrative districts participated in the poll.

\section{$3 \quad$ Results}

\subsection{Connection Hubs in the Capital}

The co-authors believe that arterial roads have historically served as dominant urban elements. Even medieval centres of built urban environments, known for their circular design, appeared at the crossings of major roads, trade routes, and geopolitical hubs. The main routes ran through city centres and determined urban planning patterns. Incremental development of road networks was responsive to the needs of interurban and intraurban travelling. In the modern era, road building gained momentum as the number of vehicles went up, bringing the contradictions typical for urban living as the main life style in the $21^{\text {st }}$ century. One of these is the contradiction between development of urban industry and transport, on the one hand, and the need to make the lives of urban residents more 
comfortable, on the other hand. The travel speed in a contemporary megalopolis keeps slowing down, thus, reducing the accessibility of particular urban districts.

The data of the survey conducted among the residents of Moscovsky town, which is a part of the capital agglomeration, prove the gravity of transport problems in the megalopolis.

Traffic problems constitute the curse of every major megalopolis in the current century. This problem forces urban authorities to address the information modelling of traffic flows. In this paper, the co-authors will limit their research to particular aspects of a transportation system as the framework of the architectural structure of a megalopolis. Here, the coauthors will analyze the model of a horizontal city, or the city stretched along a major arterial road or a network of thoroughfares, including motor ways and railroads.

In the $21^{\text {st }}$ century, both specialists and active members of the civil society contribute to development of a favourable architectural planning environment. Sometimes actions, initiated by civil activists, are far from being conventional, and they even turn outrageous; such actions will be discussed further.

Let's provide particular facts that will enable us to understand and assess the main trends in urban transportation and its development. According to the media sources, the Russian capital will accrue more and more toll parking lots every year. However, $15 \%$ of respondents believe that toll parking is a vehicle that serves to reduce the number of cars in Moscow streets (the profit making nature of parking services is to limit the growth of the private car fleet in Moscow), although the majority of our respondents don't agree with this statement. A substantial share of our respondents (47\%) is against the spreadout of toll parking lots in Moscow. Media agencies have identified another initiative, announced by the Moscow legislators, who propose to tax a second vehicle owned by a Moscow household. All initiatives, including those that are being proposed and already introduced by the urban authorities make us address the pattern of recent development of European megalopolises, including the exponential growth of the number of vehicles, including cars, owned by urban residents. Any limitations introduced by the urban authorities are to assure the top priority development of the public transport network at the expense of privately owned vehicles.

Let us address statistical data. In 2011 - 2012, the Moscow metropolitan area built a number of new roads and restructured several old ones. At the same time, 227 bridges, tunnels and elevated roads were built in the capital. Their total length was estimated at 815 kilometers. The city launched a barrier free environment for those who travelled on foot. In 2011 - 2018, 215 pedestrian crossings were built in Moscow. Moscow road services redesigned and built 14 junctions at the Moscow Automobile Ring Road.

These are some of the results attained by the Moscow road building authorities.

One of the actions, aimed at the optimization of the road network, consisted in the introduction of new public transport routes. Wherever it was necessary and possible, urban authorities reintroduced street car routes. For example, urban authorities reproduced the street car route past the Belarussky railroad station, the "western gates to the megalopolis." New models of street cars can take urban residents and guests to any district. An integrated transportation policy and development of the subway system constitute the top priorities of the Moscow metropolitan area. Since 2011 and until now, urban authorities have commissioned 121 kilometers of new subway lines, launched seven electric engine houses, and built 84 subway stations. Development of the transportation network produces a positive impact on the construction industry. Improvement of the transportation infrastructure boosts the capitalization of Moscow realty: public transport routes have made remote residential areas easier to access.

Media agencies frequently mention the construction of hubs. They serve as transit points connecting railroad stations, located in the centres of megalopolises, and terminal 
stops of subway networks. Hubs ensure convenient connection between different means of public transport. The researchers believe that new hubs will reduce traffic in Moscow streets. Specialists have identified that hubs will reduce the city's traffic by $7 \%$. Those hubs which are in operation now are being improved, and new ones are being built (construction of Salaryevo hub; restructuring of railroad squares, etc.). 251 hubs are being built, 154 have been completed. [1] $23 \%$ of our respondents are sure that intercepting parking lots and hubs can solve the transportation problems in the capital, while $35 \%$ believe that even these actions cannot help the megalopolis to solve its traffic problems, as development of the traffic network intensifies traffic flows. Moreover, construction of hubs lags behind the ever growing number of vehicles owned by Moscow households.

Engineering structures are being built in close proximity to Moscow hubs [2]. Back in 2002, a decision was made to construct a hub in the square of the Paveletsky railroad station. It's important that pedestrian traffic design was part of the project. A pedestrian crossing is being constructed in the central part of the railroad square. When it's ready, passengers will be able to walk from the platform to the underground parking lot and back. The underpass leading from the transit zone of the hub to the subterranean floor of the railroad station is located under the square. The project investments have already reached 5 billion RR. A huge pit has been excavated in the central part of the square (it is 40 meters deep); however the shopping centre has not been built yet. In 2018, when the project was close to completion, there emerged a slim ray of hope that the commissioning of the subterranean parking lot would not be postponed any longer and that the pit would be converted into the "people's park" with a hub above it. The construction work initiated in 2016 is to be completed in 2020. After that the parking lot that is in operation now will turn irrelevant: today this is the point of departure for numerous bus routes to various Russian regions. The majority of drivers will leave their cars at the subterranean parking lot. Above it, taxi drivers registered with the Moscow Department of Transport will have the right to park their vehicles. The exit from the underpass will get a glass roof, and another passenger crossing will be constructed next to it.

It is noteworthy that this project, same as many others, is being implemented at the moment. Therefore, residents of the megalopolis will assess the results of the restructuring process in the future.

The transport hubs near Salaryevo metro station deserves special attention. A metro station, an international bus station, an intercepting parking, stops of ground urban passenger transport and also Salaris shopping mall, which can potentially give to Moscow more than 6 thousand jobs, make up the hub. "All the parking spaces were occupied earlier, but there are five thousand parking now", the Moscow mayor noted, while opening of the international bus station [3]. 15 platforms are equipped for arrival and departure of buses of international flights. In total the bus station will serve up to 250 suburban and international trips a day. Routes of urban transport became more convenient. For the last A settling-andturning site is built for the urban transport, the circular road will be unloaded. Construction of one more turning site is planned [3]. Some measures are taken for of the hub territory improvement. It is important to make waiting for a bus comfortable for passengers. Lawns are made, trees and bushes are planted, benches, ballot boxes are established, cycle parkings are equipped in the hub territory. According to the experts, the transport hub will be able to serve 115 thousand passengers a day in the nearest future.

Hubs, created on the outskirts and in the center have a complex of functions as they carry out not only transport tasks, but also solve the problems of forming of the urban environment. Hubs have to become the new reference points of the districts with sports, entertaining and business infrastructure [4]. 


\subsection{Public Transport Lanes in the Moscow Streets and Arterial Roads}

Public transport lanes in Moscow streets is presented by the municipal authorities as the action aimed at the development of the barrier free environment for pedestrians and public transport passengers. Representatives of the Moscow Department of Transport are sure that public transport lanes will accelerate the speed of public vehicles running along two hundred routes. The availability of public transport lanes can reduce the interarrival time period. According to Moscow road services, the total length of public transport lanes reached 329 kilometers in early 2018. According to the estimates, made by the Department of Transport, over 2500000 people use public transport lanes every 24 hours.

The transport authority has made a point that public transport lanes speed up buses and trolley buses by $15 \%$, while the risk of accidents involving public transport vehicles goes down. According to M. Liskutov, Director, Department of Transport, "Today about $70 \%$ of all morning and evening trips are taken by public transport, that's why we continue to develop it and to make trips more comfortable for Moscow passengers." [5] What do urban authorities think about public transport lanes? They consider them as a most efficient instrument that serves to cut expenses and comply with the time table, as well as a barrier free lane for medical ambulances and other emergency service vehicles.

\section{3 "Smart Transport": Is it Reality or a Dream of Urban Planners?}

Subway and electric buses are hi tech means of urban transport. Their development is to make travelling around the megalopolis more comfortable for pedestrians. In this paragraph, the co-authors offer a retrospective overview of electric vehicles in megalopolises in the $20^{\text {th }}$ and $21^{\text {st }}$ centuries.

Principal Moscow highways have already hosted bus routes that connect the city centre with the Moscow Automobile Ring Road. Urban authorities have already commissioned hubs at subway stations, designated to connect the centre of the megalopolis with far-off districts of New Moscow. However, comfortable, environmentally friendly, and fast transportation is yet to be organized in the city. Traffic surveillance is digitalized. Electronic displays, informing passengers about the time to arrival of public transport vehicles have been installed at urban stops and on the platforms of suburban trains.

More public vehicles run on electricity. Moscow Department of Transport should have replaced the fleet of public vehicles by mid 2016. By the end of 2016, the Moscow fleet of buses had received new 261 vehicles, and 633 more vehicles are to arrive soon [1]. Against this background, the number of trolley bus routes in the city centre goes down. Our questionnaire comprised the following question: "Do you support the replacement of trolley bus routes by bus routes?" $31 \%$ of the respondents are against the initiative (see Fig. 1).

In spite of the widespread belief, the most part of the respondents interviewed by the employees and students of MCUSE do not agree with the thesis that the trolleybus is a hindrance for movement of individual motor transport. The distribution of answers for the question "Do You Consider That the Movement of Trolleybuses Interferes with the Organization of the Movement of Personal Vehicles?" is presented in Figure 2. Only 17.9\% of answers in the affirmative the matter, and $61.5 \%$ of answered "No". $20.5 \%$ of respondents did not choose their answer for the question. 


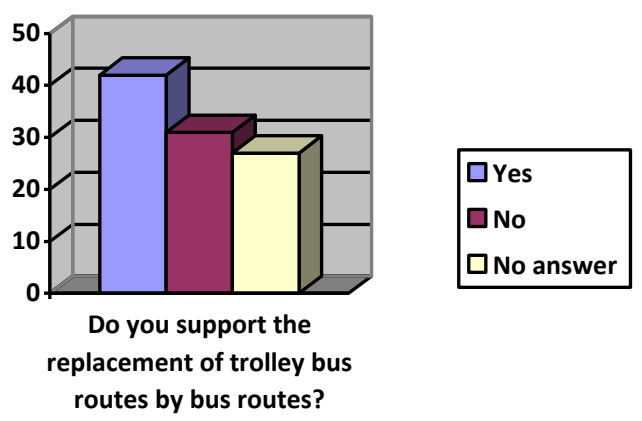

Fig. 1. Transport preferences of Moscow residents, according to the findings of our sociological survey.

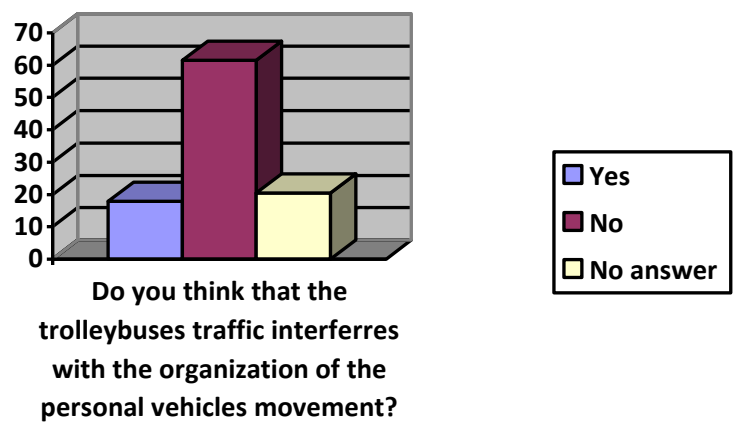

Fig. 2. Distribution of answers for the question "Do You Consider That the Movement of Trolleybuses Interferes with the Organization of the Movement of Personal Vehicles?"

Ecological factors and rising fossil fuel prices contribute to development of powerdriven vehicles. Our respondents believe that trolley buses and electric buses are more environment friendly than other means of public transport. They have already proven efficient.

The need to improve the ecological situation in the sphere of transport is realized by the Moscow authorities. They connect such improvement with the replacement of routes of buses and taxi with different types of the electric transport. M. Liksutov, the Head of Department of transport and development of road and transport infrastructure, said that "the start of electro-bus opened a new stage of the development of environmentally friendly transport in the Russian capital". At the same time? it should be noted that 100 such cars had been launched in Moscow by spring of 2019, and the quantity of electro-bus will increase up to 900 in 2020. The further development of such type of transport (according to M. Liksutov) requires some "support by business and passengers». However? the development of network of the electric transport takes place in the capital region not only thanks to the entrepreneurs, who invest in the transport development, but also through the widespread introduction of new technologies. It is necessary to name the single-section tram "Young Lion", equipped with the system of video surveillance, the electric train "Moscow" having the low level of noise and supplied with end-to-end pass through cars, the first Russian "Zetta" electric vehicle among the technical innovations which already appeared on the highways of the capital and in Moscow "subway". And while the trains of 
the new subway train are already started on the Tagansko-Krasnopresnenskaya Line, the tram and electric vehicles will appear on roads of the capital at the end of 2019. The Moscow authorities do the main rate on electrobuss.

Thanks to electric buses, pollution of the urban environment reduces, noise level goes down, and public transport turns more convenient. In the short term, urban authorities are going to give up buying diesel-fuelled and combustion-engine vehicles, and any dieselfuelled buses will be replaced by electric buses in the mid term. The researchers are convinced that more e-vehicles will be in use in a few years. Facts of history have proven that in the age of motor cars e-vehicles were considered as the top priority trend. In 1899, 1,575 e-vehicles versus 936 motor cars were produced in the USA. [5] In the $21^{\text {st }}$ century, Japan, the most technologically developed country of the post-industrial world civilization, decided to revive its e-vehicle projects. In the autumn of 2015, Nissan announced its new project - Nissan Leaf, it can cover the distance of $250 \mathrm{~km}$ without any extra charging. [6]

China does not lag behind the countries of the world civilization core. Its megalopolises continue to grow, absorbing rural districts. According to data of media the electric transport in the Chinese megalopolises made up to $55 \%$ of the total number of vehicles. The most part of the park of electric cars are electro-buses. Nowadays so-called "King Kongs" (cars with electric motors) go about the cities of the People's Republic of China. The benefit and at the same time the challenge of this model is their silent running. The pedestrian often does not hear an approaching bus and risks to get under its wheels. Beside electro-buses the citizens in the Chinese megalopolises widely use their individual vehicles: electromotorcycles and mini-bikes [7,9].

However, no mass use of e-vehicles is possible without the deployment of an extensive network of charging stations, and their number should be, at least, the same as the one of gasoline stations. It is noteworthy that fast charging buses have been purchased for the Russian capital. [10] Urban authorities in Moscow think that the purchase of electric buses is a great stride towards improvement of transport routes in the megalopolis, the stride similar to transition from horse-drawn to power-driven trams in the 20ies of the 20th century.

The problem with charging of individual vehicles is solved a little easier: mini-baizes can be loaded and at home, for example, on a staircase.

If we compare the actions offered by the society and urban authorities, we will find out that development of power-driven vehicles will be the top priority in the short term. These vehicles include trolley buses, dual-mode buses, high-speed trams, and subway. They are widely used in the so-called "cities of the future", including Songdo in South Korea. However, Russia has kind of a prejudice against trams and trolley buses. [11] According to the findings of the poll, conducted at the university of civil engineering, the majority of respondents prefer to travel by bus, although a substantial share of the respondents (up to $30 \%$ ) do not see the difference between power driven public transportation vehicles and other means of transport.

And nevertheless, the decision of the Moscow authorities on the replacement of transport with gas-petrol engines with electro-bus-s is estimated by specialists to be ambiguous. The matter is that the electro-bus maintenance is by three-four times more expensive, than the regular bus maintenance. And this with the fact that the efficiency of the electric motor is three times lower, and the efficiency of electro-cars sharply decreases during the cold period of year. The electro-bus is adapted for driving on wide direct highways which are located on the outskirts of the city. In the center of the megalopolis with its curve narrow lanes and chaotic building of a benefit remain at buses. Stations of recharge are necessary for service of the electric transport, expansion of thermal power plant network which are under construction in the residential suburb is also required; that 
will increase the impact for the environment. The last circumstance makes the thesis about "purity" of electro-bus improbable [12, 13, 14].

All this should be considered to the city authorities which set the task to force the notelectrified transport out from the Moscow streets and highways.

\subsection{Creation of a transportation network in the southwest of the capital megalopolis. Will the subway take you to the summer cottage?}

According to the requests and needs of citizens [15], the executive authority of the Russian capital continues laying of lines of the subway connecting the center of the capital and its remote areas. In his interview to the city newspaper the Moscow mayor tells about a wide scope of work on the expansion of the lines of capital "subway" in the southwest, the northeast and the South of the megalopolis. The driving of the second tunnel of the southern site of the Big Ring Line (BRL) from the Vorontsovskaya station to the Novatorov Street station began in 2018. Using social networks, S. Sobyanin informs the citizens abot the work progress in detail. At the same time the network of tunnels is under construction in the northeast: The tunnel will connect the Stromynka station to the Rzhevskaya station. On the southeast site of six Moscow Metro tunnels from the Aviamotornaya station to "Stromynka" have been already passed.

However, the subway reached not all the settlements and districts of the capital. Nearly half a million of the megalopolis residents live in new territories, where the construction of stations of the subway is only developed.

The popularity of different types of transport among passengers is confirmed by the data of the conducted among the inhabitants of Moscow and Troitsk Administrative districts. Figure 3 presents the results of the poll: "What type of public transportation do you use most often?" More than a half of residents of the city, situated near Moscow (55\%) chose the subway. $6 \%$ use taxi, $9 \%$ - bus, 30\% - individual cars, $0 \%$ chose the electric train. Answers of the Troitsk Adminstrative District residents, (this district is the most remote from the center) were not the same: $0 \%$ chose the subway, $5 \%$ - taxi, $38 \%$ - individual cars, $48 \%$ - bus and $9 \%$ - electric train. The residents of the Troitsk administrative district did not name subway among the vehicles as it is unavailable for them.

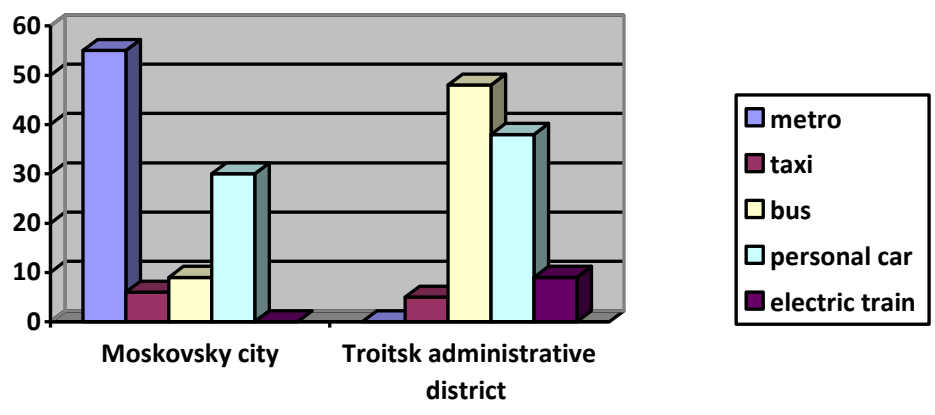

Fig. 3. The results of the poll among the inhabitants of Moscow and Troitsk administrative districts "What type of public (personal) transport do you use most often?"

There were neither the railway service, nor lines of the subway in some territories of New Moscow (e.g., in the city Moscovsky). But the area develops actively, new metro stations has opened. At the same time metrobuilders are not going to be satisfied with what has already been achieved. According to the development plan in Troitsk and Novomoskovsk Administrative Districts two branches of the capital subway will be passed 
at once, and the Sokolnichesky line will go up to the settlement the Communard and Potapovo stations. In addition to Sokolnicheskaya one more branch of the Moscow subway, Kommunarskaya will come to new territories of Moscow soon. In 2018 builders started the first stage of its construction. Such boundaries will be reached by the Subway in the southwest of the capital in 2020-2023.

Let's pay attention to the poll results in the Troitsk administrative district. Some answers need further judgment. In spite of the fact that it is the district of the capital, most remote from the center, nevertheless, the respondents do not put the solution of the transport problem on the first place. Answering the question about the main direction of the development of the district the interviewed inhabitants gave the following answers (Figure 4):

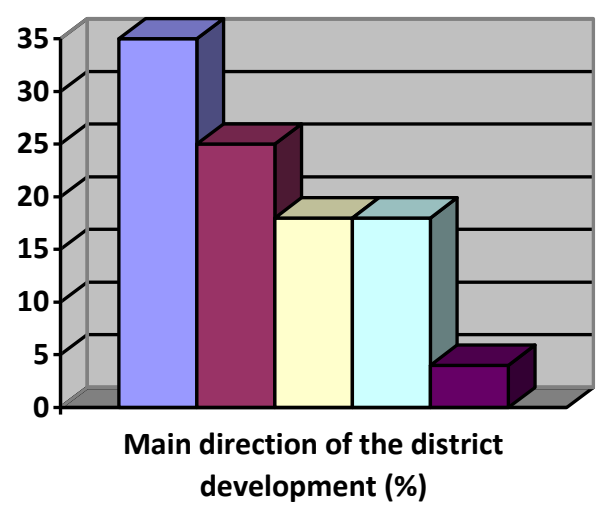

\begin{tabular}{|l|}
\hline \\
Modernizationof \\
policlinics and \\
hospitals \\
$\square$ Opening of new \\
recreation places \\
$\square$ Transport \\
infrastructure \\
imvrovement \\
$\square$ Cultural \\
organizations \\
renewal \\
Streets \\
improvement
\end{tabular}

Fig. 4 The Main directions for the development of the district in assessment of residents of the Troitsk district of Moscow (according to the vote on the vk.com/moskiev portal)

Only $18 \%$ of the respondents consider the improvement of transport infrastructure to be such a problem. The same quantity of the respondents chose the item "Updating of Cultural Organizations". The much bigger quantity of inhabitants supported modernization of policlinics and hospitals (35\%) and opening of new vacation spots $(25 \%)$. Only $4 \%$ of the respondents gave preference to the streets improvement.

\section{Conclusions}

Vehicles take on greater importance in the present-day urbanized world. Hence, the attention of urban authorities is focused on them, and a lot is done to streamline their travel patterns. Traffic delays in rush hours have long been a global urban problem that forces urban residents to switch to bicycles, to walk or to rely on electric cars or buses. In this article, the co-authors have analyzed particular actions aimed at the reorganization of transport links in the Russian capital. The co-authors focus their attention on the actions that should have made urban space more technology intensive, on the one hand, and biosphere compatible, on the other hand. The co-authors acknowledge that transport systems of major cities need improvement and alterations due to the accrual of contradictions both in the area of passenger traffic and in the area of urban planning and city management. In some cases these contradictions cause transport delays due to the growing car fleet, in other cases they are the consequence of the insufficient number of parking lots and absence of public transport routes connecting particular urban districts, let alone the accumulation of pollutants in the atmosphere of urban centres. The content of 
methane, nitric oxide, volatile hydrocarbons can exceed acceptable value by hundreds or even thousands of times. Replacement of diesel-fuelled vehicles by electric vehicles is the solution. Sometimes transport conflicts are the consequence of contradictory concerns expressed by groups of urban residents.

The measures for the satisfaction of all groups of urban population were considered in the article. Special attention was paid to the measures for creation of comfortable conditions of movement in the southwest of Moscow.

The co-authors considered the main trends in development of transport infrastructure in the Russian capital. According to the poll findings, urban residents prefer a comprehensive transportation policy to unpopular actions as toll parking and limitation of the number of cars per household. Urban residents welcome the development of Moscow subway and construction of hubs. The intercepting parkings and transfer hubs which are under construction near some metro stations and railway stations inspire great hope for the city authorities. Thanks to construction of such hubs it is possible to eliminate the barriers for motorists and passengers of public transportation during their movement in the megalopolis.

At the same time, it is possible to conclude that plans which are adopted by the Moscow government for the next four years are quite ambitious. If to consider the terms and speed of input of objects into maintenance, then the quantity of routes, underground highways and tunnels, which will be built in the road sphere of the capital within four years, will be 2.5 times more than during the last eight years. The co-authors have also analysed the routes of electric buses. They let the city reassume the function of nature protection, although some conservatively minded residents think that fossil fuel vehicles are better.

\section{References}

1. Bolshaya Moskva, 36 (3) (2015)

2. E. Vasilyeva, MATEC Web of Conferences, 170, 05005 (2018)

3. E. Yakupova, Moskovsky today, 18 (139), 1 (2019)

4. M. Klinsky, Moscow prospect, 20 (1245), 2 (2019)

5. 5 Semenov. D., Vechernyaya Moskva, 2, 27847 (2018)

6. I. M. Golovinykh, Transport: science, technology, management, 10 (2) (2009)

7. V. Fedotov, Evening Moscow, 21 (28243), 7 (2019)

8. N. Rusina, Moscow Prospects, 32, 1212 (2018)

9. The price for the refined Nissan Leaf has been announced. URL: http://autotesla.com/obyavlena-cena-na-obnovlennyj-elektromobil-nissan-leaf-vssha/\#more-11212 Date of access: October 14, 2018

10. S.A. Adasinsky, Urban transport of the future. Moscow, Nauka Publ. (1979)

11. D. Gabarda, New transport systems of urban public transport. Moscow, Transport Publ. (1990)

12. K. Agiton, Alternative globalization Moscow, Gileya Publ. (2004)

13. Kopenhagen: changes in the Northern city from 1960 till 2011 URL: http://maxkatz.livejournal.com/53298.html?page=1 Date of access: November 14, 2015

14. S. Gordeyev, M. Blinkin, Arkhnadzor, 10 (2008)

15. A. Mottaeva and E. Vasilyeva, MATEC Web of Conferences, 239, 04019 (2018) 